\title{
Distribution of Leaf Flavonoid Aglycones and Glucuronides in the Genus Phaseolus and Related Genera
}

\author{
Michelle L. Poe ${ }^{1}$, Andra Bates ${ }^{1} \&$ Joseph Onyilagha ${ }^{1}$ \\ ${ }^{1}$ Department of Biology, University of Arkansas at Pine Bluff, Pine Bluff, Arkansas, USA \\ Correspondence: Joseph Onyilagha, Department of Biology, Mail Slot \#4972, University of Arkansas at \\ Pine Bluff, Arkansas, 71602, USA. Fax: 870-575-4602. E-mail: onyilaghaj@uapb.edu
}

Received: July 4, 2013 Accepted: July 15, 2013 Online Published: September 9, 2013

doi:10.5539/ijb.v5n4p36 URL: http://dx.doi.org/10.5539/ijb.v5n4p36

\begin{abstract}
Ninety-six species and hybrids of the genus Phaseolus and related genera, Dysolobium, Macroptilium, Strophostyles, and Vigna are surveyed for their leaf flavonoid (flavone/flavonol) aglycone and glucuronide distribution patterns. The aim is to determine whether the distribution patterns of certain flavonoid aglycones and/or glucuronides are restricted in each genus and hence, could be used to delineate the genus. The results show that flavonol aglycones (kaempferol and quercetin) are more frequent in the entire group than the flavones (luteolin and apigenin). Kaempferol is more prevalent than quercetin in the genus Macroptilium, while Strophostyles accumulates mainly quercetin. There is generally no restricted pattern for a particular type of flavonoid aglycone in Phaseolus and Vigna genera. Results also show the presence of flavonoid glucuronides in six out of 18 species of Phaseolus surveyed, but are absent in all the species of Vigna, Macroptilium, and Strophostyles. The situation in Dysolobium is inconclusive. A flavonoid band moved toward the anode during electrophoresis (a positive test for the presence of glucuronide) but glucuronic acid was not detected during subsequent analysis. In the genus Phaseolus, all the species and cultivars that accumulate flavones such as $P$. coccineus, $P$. ricciardianus and P. parviflorus accumulate flavone glucuronides, while $P$. vulgaris, $P$. tuberosus and $P$. zebra accumulate flavonol glucuronides.
\end{abstract}

Keywords: Phaseolus, flavonoid, quercetin, kaempferol, luteolin, apigenin, glucuronide, flavone, flavonol

\section{Introduction}

Species of the plant genus Phaseolus and its relatives are generally known as "beans". They form important staple food crops in many countries especially in some tropical areas where protein rich beans could be substituted for meat proteins. Few species are cultivated. Two of the most important ones are P. vulgaris, which thrives in the temperate regions and $P$. lunatus, which prefers the tropical regions. The majority of the species is wild and is distributed in all the climatic regions. The potentials of these wild species are not yet fully realized.

The precise definition of the genus has long been unclear, mainly because it is difficult to distinguish it clearly from Vigna (Evans, 1980; Onyilagha, 1993; Onyilagha \& Shahidul, 2009). This confusion may have started early in Linnaean taxonomy. Linnaeus included eleven species in his genus, namely, Phaseolus vulgaris, $P$. coccineus, $P$. lunatus, $P$. inamoenus, $P$. farinosus, $P$. vexillaatus, $P$. helvulus, $P$. alatus, $P$. caracalla, $P$. radiatus and $P$. max (Linnaeus, 1753).

De Candolle divides the genus Phaseolus into two sections, Euphaseolus and Strophostyles with five subgroupings in the first and two in the second. These are however heterogeneous and do not provide a satisfactory basis for classification (Candolle, 1825). Bentham gives a synopsis of the genus. He describes 85 species distributed in seven sections: Drepanospron, Euphaseolus, Leptospron, Strophostyles, Lasiospron, Microcochle and Macroptilium (Bentham, 1837). In his later work, he dropped Lasiospron and Microcochle and added Dysolobium. Since that time, Dysolobium and Macroptilium are recognized as distinct genera by Prain and Urban respectively.

In his review, Piper recognized eight sections: Sigmoidotropis Piper, Ceratotropis Piper, Lasiospron, Macroptilium, Microcochle, Cochliasanthus (Trew) Piper, Leptospron and Euphaseolus (Piper, 1926). In another revision of the genus, Verdcourt recognized Macroptilium as a genus after Urban and the treatment of Sigmoidotropis, Ceratropis, Lasiospron and Cochliasanthus as sub-divisions of Vigna (Verdcourt, 1970). Phaseolus was therefore limited to only 50 species. To date, this treatment serves a practically useful classification 
suitable for most plant breeders, but there are still some American lowland types which are Vigna-like and some African species which have Phaseolus type characteristics (Marechal, Mascherpa, \& Stainier, 1978). The latest revision of Marechal et al. recognized three sections, which include a large Euphaseolus and smaller Alepidocalyx and Minkelersia (Marechal, Mascherpa, \& Stainier, 1978). They maintained earlier elevations of Macroptilium, Dysolobium and Strophostyles to distinct generic levels. It is important to note, however, that the above revisions of the genus were based largely on morphology and related characters. Phytochemical data were absent or rare.

Some accounts have appeared in literature where biochemical data have been employed to help resolve taxonomic problems in the Leguminosae. For example, seed extracts of Lathyrus yielded amino acid patterns which reflect species differences (Bell, 1962). Lackey presented a classification of the tribe Phaseoleae based on canavanine amino acid distribution in seeds of species (Lackey, 1977). Ingham studied the systematic significance of phytoalexin compounds in the Phaseoleae (Ingham, 1990). Webb and Harborne studied the sectional classification of the genus Vicia based on leaf flavonoid aglycones patterns (Webb \& Harborne, 1991). Seneviratne and Harborne gave an account of the taxonomic usefulness of constitutive flavonoids and induced isoflavonoids in the genus Vigna (Seneviratne \& Harborne, 1992). Other more recent applications of biochemistry in taxonomic studies include Williams et al. (1995), Onyilagha and Shahidul (2009), Onyilagha et al. (2003, 2009), etc.

The actual function(s) of glucuronides in plants is yet to be elucidated and there is doubt as to whether it is a true sugar. However, we speculate that it may be one of the defense molecules, which may protect the plant species against herbivores. Our application of the presence and/or absence of flavonoid glucuronides in a taxonomic study is novel and it is hoped that it will help to delineate species or generic boundaries in the legumes.

The aim of this study is to bring to life the taxonomic problem of delineating Phaseolus from other relatives by presenting the distribution pattern of leaf flavonoid aglycones and glucuronides in the entire group, and this new information may provide useful taxonomic data during any future revision of the genus Phaseolus or the entire group.

\section{Materials and Methods}

Most of the seed samples were obtained from the National Botanic Gardens, Belgium, the United States Department of Agriculture (Plant Introductions unit), and CIAT. In the text/Table, all samples from Belgium have the letters 'N.I.' prefixed to their accession numbers; those from U.S. have the letters 'P.I.'; while those from CIAT are prefixed with the letter ' $G$ '.

\subsection{Planting of Seeds}

The seeds were initially scarified and soaked in deionized water overnight (Onyilagha, 1993). The scarification allowed easy water penetration into the cotyledons thereby helping to break dormancy. Soaked seeds were transferred into petri dishes containing a small quantity of wet vermiculite. They were covered and placed in dark isothermal conditions of $25{ }^{\circ} \mathrm{C}$ for up to three days. The seeds or seedlings were transferred into six inch pots containing high nutrient soil and the pots placed in the glasshouse. Watering was normal and was done every two days. Nutrients (N.P.K., ratio 1:1:1) were fed from 2-3 weeks after germination. A one week feeding interval was maintained throughout the growing period (Onyilagha, 1993). Healthy leaves were harvested from mature plants. Samples were completely air dried, and stored in the laboratory. This served as the source of materials for biochemical analyses.

\subsection{Biochemical Extractions and Analyses}

Biochemical compounds were studied using standard procedures (Holt et al., 2010; Onyilagha et al., 2012). Dried leaf samples were boiled in $70 \%$ ethanol for about 10 minutes and left to stand overnight for completed extraction. The extract was filtered and evaporated to dryness using a rotary evaporator. Purification of glycosides was done by 1-D paper chromatography (3 MM paper) in at least three solvents: Butanol-Acetic acid-Water (BAW 4:1:5, top layer), $15 \%$ Acetic acid and then Water. In some cases it was necessary to further purify the glycosides in Chloroform-Acetic acid- water (CAW 1:1).

Ultraviolet spectral measurements of methanolic glycosides (neutral) were obtained using the HPLC. The glycosides were then hydrolyzed with $2 \mathrm{M} \mathrm{HCL}$ in a boiling water bath for about 30 minutes. The sample was allowed to cool. Aglycones were extracted in ethyl acetate, dried in fume cupboard, and chromatographed on cellulose thin layers $(100 \mathrm{~mm}$ ) against authentic markers in 50\% Acetic acid, BAW, and Forestal solvents (Onyilagha et al., 2003).

Paper electrophoresis was carried out to determine the presence or absence of glucuronides in all the pure samples. A small amount of pure glycoside was applied as separate spots on a $3 \mathrm{MM}$ paper $\left(11^{\prime \prime} \times 8^{\prime \prime}\right)$. Glucuronide is not present in rutin and therefore it was used as a negative marker plus a positive marker such as quercetin or 
kaempferol 3-glucuronide or apigenin or luteolin 7-glucuronide. Electrophoresis was carried out for 2.5 hours at $400 \mathrm{~V}$ in acetate buffer $\mathrm{pH}$ 4.4. Dried electrophoretic papers were examined under $\mathrm{UV} / \mathrm{NH}_{3}$ for any migration toward the anode $(+)$. Rutin does not migrate due to absence of glucuronide.

\section{Results}

Results of this survey are presented in Table 1. Apart from P. coccineus, P. parviflorus, and P. ricciardianus, which accumulate flavonoids based on flavone (apigenin and/or luteolin), all other species of Phaseolus surveyed so far accumulate flavonoids based on flavonols (quercetin and/or kaempferol) (Figure 1). In the genus Vigna, only the species $V$. praecox has so far been found to accumulate flavones. Hence, the results tend to suggest that the entire group is dominated by flavonols. Myricetin flavonoid was found absent in all the genera surveyed. There is no consistent agreement in flavonoid aglycone distribution in Phaseolus, even among the cultivated species such as $P$. coccineus, $P$. vulgaris, $P$. acutifolius, $P$. lunatus and P. polystachyus (Table 1). The situation is different in Vigna where there is apparent dominance of kaempferol aglycone in most of the cultivated species (V. angularis, $V$. trilobata, $V$. aconitifolia, $V$. mungo, $V$. radiate, $V$. subterranea and $V$. unguiculata).

This survey reveals that glucuronides are not universally distributed in plants. Its absence is scored when glucuronic acid cannot be detected on paper chromatograms after sugar analyses and also when there is no movement of spots to the anode during electrophoresis. We present the presence/absence of flavonoid glucuronide in Table 1. Similar to flavonoid aglycones, there is no consistency in accumulation of glucuronides in Phaseolus genus. It is present in 6 out of 18 species of Phaseolus, but absent in all surveyed species of Vigna, Macroptilium, and Strophostyles. The situation in Dysolobium is confusing. There was obvious movement of one of the flavonoid bands toward the anode during electrophoresis but glucuronic acid was not detected on the paper chromatograms after sugar analysis.

Table 1. Distribution of leaf flavonoid aglycones and glucuronides in Phaseolus and related genera

\begin{tabular}{|c|c|c|c|c|c|c|}
\hline Species & Q3'Me & $\mathrm{Q}$ & $\mathrm{K}$ & $\mathrm{L}$ & $\mathrm{A}$ & Glucuronides \\
\hline \multicolumn{7}{|l|}{ Phaseolus coccineus L. } \\
\hline \multicolumn{7}{|l|}{ Ssp. Polyanthus: } \\
\hline G35089 & - & - & - & + & + & + \\
\hline G35877 & - & - & - & + & + & + \\
\hline \multicolumn{7}{|l|}{ Ssp. Coccineus: } \\
\hline Var. coccineus N.I. 0132 & - & - & - & + & + & + \\
\hline Var. silvester N.I. 0726 & - & - & - & + & + & + \\
\hline \multicolumn{7}{|l|}{ P. ricciardianus Tenore } \\
\hline Gradina 901 & - & - & - & + & + & + \\
\hline \multicolumn{7}{|l|}{ P. parviflorus G. Freytag } \\
\hline N.I. 812 & - & - & - & + & + & + \\
\hline \multicolumn{7}{|l|}{ P. vulgaris $\mathrm{L}$. } \\
\hline \multicolumn{7}{|l|}{ Ssp. Aborigineus } \\
\hline G19892 & - & + & + & - & - & + \\
\hline \multicolumn{7}{|l|}{ Var. vulgaris: } \\
\hline Giessen 220 & - & + & + & - & - & NT \\
\hline N.I. 0613 (weedy type) & - & + & + & - & - & NT \\
\hline N.I. 0928 (wild type) & - & + & + & - & - & NT \\
\hline \multicolumn{7}{|l|}{ P. tuberosus Eaton \& Wright } \\
\hline Kn 850114 & - & + & + & - & - & + \\
\hline \multicolumn{7}{|l|}{ P. zebra Savi } \\
\hline Dijon 1306 & - & + & + & - & - & + \\
\hline
\end{tabular}


P. acutifolius A. Gray

Var. acutifolius N.I. 0576

Var. latifolius G 40066A

P. lunatus $\mathrm{L}$.

N.I. 823

Dijon 1303

P. limensis Macfadyen

P. leptostachyus Benth.

N.I. 1037

P. polystachyus (L). Britt.

P.I. 264607

P.I. 264608

P. microcarpus Mart.

N.I. 708

P. filiformis Benth.

P.I. 535300

N.I. 0587

F 1147

P. oligospermus Piper

N.I. 1116

P. xanthotrichus Piper

N.I. 1239

P. micranthus Hooker \& Arn.

N.I. 1107

P. angustissimus A. Gray

N.I. 0788

P. bolivianus

Kew 10968

P. polymorphus S. Wats.

Kew, Parry \& Palmer

P. wrightii A. Gray

Kew 1347

P. anisotrichus Schlecht

Kew 13163

Strophostyles helvula (L)

Elliott

P.I. 215295

S. leiosperma (Torrrey \& A.

Gray) Piper

P.I. 215298

S. umbellata (Willd.) Britt.

N.I. 0317

Dysolobium apiodes 
(Gagnepain) Marechal

CIAT 4596

Macroptilium atropurpureum

(DC.)Urb.

N.I. 101

N.I. 0328

Q 883

M. bracteatum (Nees \& Mart.) Marechal \& Baudet

N.I. 0327

Kew 23251

M. lathyroides L. Urban

N.I. 0384

Ksukuba 587

M. fraternum (Piper) Lackey

N.I. 1307

M. erythroloma (Benth.)

Urban

N.I. 698

M. gibbosifolium (Ort.)

Delgado

P.I. 322595

N.I. 697

M. gracile (Poepp.) Urban

Kew 793

M. Supinum

N.I. 872

Vigna luteola (Jacq.) Bentham

P.I. 196813

V. Caracalla L. Verdc.

P.I. 146800

V. glabrascens Marechal

P.I. 207655

$V$. longifolia (Benth.) Verdc.

Kew-Irwin

$-\quad+\quad+\quad-\quad$ NT

$V$. parkeri Baker

N.I. 1315

Archbold 1456

$V$. marina (Burman) Merrill

Q 821

$V$. reticulata Hooker

Flock 77A

V. frutescens A. Richard

NT

NT

NT

NT

NT

NT

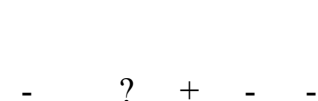

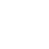

$++$ 
Kew 846

$V$. Oblongifolia A. Richard

$$
\begin{aligned}
& \text { NI } 124 \\
& \text { NI } 389
\end{aligned}
$$

$V$. praecox Verdc.

Kew 19065

$V$. juncea Milne-Redhead

$$
\text { Kew } 1947
$$

V. triphylla (R. Wilczk)

Verdc.

Kew 2817

N.I. 100

$V$. catjang Walp

Dijon 1359

V. angularis (Willd.) Ohwi \& Ohashi

$$
\begin{aligned}
& \text { AA1 } \\
& 5125 \\
& 5152
\end{aligned}
$$

Ahevi 936

V. trilobata L. Verdc.

N.I. 0251

N.I. 0258

V. aconitifolia (Jacq.)

Marechal

MoA1

502

512

PG-I

$V$. mungo L. Hepper

BA1

TVm1

T-9

3118

V. subterranea L. Verdc.

Roger 3

Ankpa-Nigeria

Tali-Ghana

Vigna umbellata (Thunb.)

Ohwi \& Ohasi

436

4022

4042

NT

$-\quad+\quad+\quad-\quad$ NT


TVum1

V. unguiculata L. Verdc.

Ssp. Unguiculata:

CA I

Ssp. Cylindrical:

Hawarimae

Ssp. Sesquipedalis:

361

Bushitawo

Ssp. Sinensis:

P.I. 29354

Key to Table 1: $\overline{\mathrm{Q} 3}$ 'Me $=$ quercetin 4' methyl ether; $\mathrm{Q}=$ quercetin; $\mathrm{K}=$ kaempferol (M, Q, K $=$ flavonols); $\mathrm{L}=$ luteolin; A = apigenin (L, A = flavones); NT = not tested; $(+)=$ present; $(-)=$ absent; $($ ?) = undetermined.

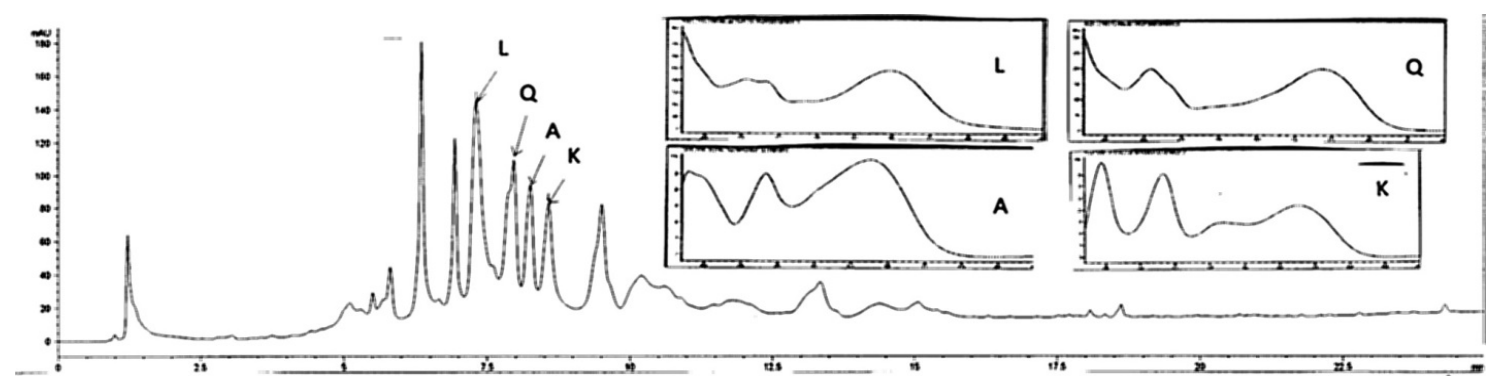

Figure 1. Chromatogram showing luteolin (L), quercetin (Q), apigenin (A), and kaempferol $(\mathrm{K})$ as well as corresponding uv-spectrum

\section{Discussion}

This study appears to support earlier separations of the genera Macroptilium and Strophostyles from Phaseolus. While there is biochemical relationship between the three genera on account of flavonoid accumulation, however, flavonol aglycones are restricted in Macroptilium and Strophostyles genera, a characteristic which could be used in defining both genera. Furthermore, kaempferol appears to dominate in the genus Macroptilium while Strophostyles seems to accumulate more of quercetin aglycones. Hydrolysis was not achieved in Dysolobium because of the presence of flavonoid C-glycosides (Williams,1995). Distribution of flavonoid aglycones agrees in the existence of a complex relationship between Phaseolus and Vigna (Marechal, Mascherpa, \& Stainier, 1981). There is apparently no defined pattern of flavonoid distribution in the two genera, an observation which is consistent with Williams et al. (1995). Most of their species contain flavonol (quercetin and kaempferol) aglycones while few others contain either of the two aglycones. In the genus Phaseolus, it is interesting to note that all the species and cultivars that accumulate flavone aglycones such as $P$. coccineus, $P$. ricciardianus, and $P$. parviflorus accumulate flavone (apigenin and/or luteolin) glucuronides, while P. vulgaris, P. tuberosus, and P. zebra accumulate flavonol glucuronides.

We observe that although leaf flavonoid aglycone and glucuronide distribution are not adequate enough to resolve the complex relationship between Phaseolus and Vigna, however, their distribution patterns in Vigna, Strophostyles, and Macroptilium suggest that they may be useful in the characterization and/or revision of the genera. Further investigations are necessary in the presence/absence of glucuronides in Dysolobium. We surveyed only one species (D. apiodes), but the true situation will be known when many more species are surveyed.

\section{References}


Bell, E. (1962). Associations of ninhydrin-reacting compounds in the seeds of 49 species of Lathyrus. Biochemical Journal, 83, 225-229.

Bentham, G. (1840). Commentationes de leguminosarum generibus. Sollinger: Rohrmann und Schweigerd.

de Candolle, A. (1825). Memoires sur la famille des Legumineuses. Paris.

Evans, A. (1980). Advances in Legume Science. In R. Summerfield, \& A. Bunting, (Eds.). Kew: Royal Botanic Gardens. http://dx.doi.org/10.2307/2055204

Holt, N., Luster, B., \& Onyilagha, J. (2010). Flavonoids and Insect Feeding Resistance in Camelina sativa. 68th $P A W C$ (p. 8). Tuskegee: Tuskegee University.

Ingham, J. (1990). Systematic aspects of phytoalexin formation within tribe Phaseoleae of the Leguminosae (subfamily Papilionoideae). Biochemical Systematics and Ecology, 18(5), 329-343. http://dx.doi.org/10.1016/0305-1978(90)90006-2

Lackey, J. (1977). A revised classification of the tribe phaseoleae (Leguminosae: Papilionoideae), and its relation to canavanine distribution. Botanical Journal of the Linnean Society, 74(2), 163-178. http://dx.doi.org/10.1111/j.1095-8339.1977.tb01173.x

Linnaeus, C. (1753). Species Plantarum Vol. 1. Salvius, Stockholm.

Marechal, R., Mascherpa, J., \& Stainier, F. (1978). Etude taxonomique d'un groupe complexe d'especes des genres Phaseolus et Vigna (Papilionaceae) sur la base donnees morphologiques et polliniques, traitees par l'analyse informatique. Boissiera, 28, 133.

Marechal, R., Mascherpa, J., \& Stainier, F. (1981). Taxonometric study of the Phaseolus-Vigna complex and related genera. In R. M. Polhill, \& P. H. Raven (Eds.), Advances in Legume Systematics (pp. 329-335). Kew: Royal Botanical Gardens.

Onyilagha, J. (1993). Phytochemical Studies of the Genus Phaseolus (Fabaceae) and Some Related Genera with Special Reference to their Flavonoid Patterns (p. 286). Reading, United Kingdom: University of Reading Press.

Onyilagha, J., \& Islam, S. (2009). Flavonoids and other polyphenols of the cultivated species of the genus Phaseolus. International Journal of Agriculture \& Biology, 11(3), 231-234. Retrieved from http://www.fspublishers.org/

Onyilagha, J., Bala, A., Hallett, R., Gruber, M., Soroka, J., \& Westcott, N. (2003). Leaf flavonoids of the cruciferous species, Camelina sativa, Crambe spp., Thlaspi arvense and several other genera of the family Brassicaceae. Biochemical Systematics and Ecology, 31, 1309-1322. http://dx.doi.org/10.1016/S0305-1978(03)00074-7

Onyilagha, J., Gruber, M., Hallett, R., Holowachuk, J., Buckner, A., \& Soroka, J. (2012). Constitutive flavonoids deter flea-beetle insect feeding in Camelina sativa L. Biochemical Systematics and Ecology, 42, 128-133. http://dx.doi.org/10.1016/j.bse.2011.12.021

Piper, C. (1926). Studies in American Phaseolineae. Contributions from the United States National Herbarium, 22(9), 663-701.

Seneviratne, G., \& Harborne, J. (1992). Constitutive flavonoids and induced isoflavonoids as taxonomic markers in the genus Vigna. Biochemical Systematics and Ecology, 20(5), 459-467. http://dx.doi.org/10.1016/0305-1978(92)90087-T

Verdcourt, B. (1970). Studies in the Leguminosae-Papilionoïdeae for the 'Flora of Tropical East Africa': IV. Kew Bulletin, 24(3), 507-563. http://dx.doi.org/10.2307/4102845

Webb, M., \& Harborne, J. (1991). Leaf flavonoid aglycone patterns and sectional classification in the genus Vicia (Leguminosae). Biochemical Systematics and Ecology, 19(1), 81-86. http://dx.doi.org/10.1016/0305-1978(91)90115-G

\section{Copyrights}

Copyright for this article is retained by the author(s), with first publication rights granted to the journal.

This is an open-access article distributed under the terms and conditions of the Creative Commons Attribution license (http://creativecommons.org/licenses/by/3.0/). 